\title{
Do Innovation Subsidies Policy Improve the Innovation Performance of Enterprises?
}

\author{
Xiujie Yao \\ Jinan University, Guangzhou, China \\ Email: 13129371830@163.com
}

How to cite this paper: Yao, X.J. (2019) Do Innovation Subsidies Policy Improve the Innovation Performance of Enterprises? Open Journal of Social Sciences, 7, 1-12. https://doi.org/10.4236/jss.2019.72001

Received: January 7, 2019

Accepted: January 26, 2019

Published: January 29, 2019

Copyright $\odot 2019$ by author(s) and Scientific Research Publishing Inc. This work is licensed under the Creative Commons Attribution International License (CC BY 4.0).

http://creativecommons.org/licenses/by/4.0/

\section{(c) (i) Open Access}

\begin{abstract}
To explore the relationship between the forms of innovative subsidies and corporate innovation performance and study the policy's influence factors, we have compared the two forms of innovative subsidies for government subsidies and R\&D tax super-deduction policy, by conducting an empirical study on A-share listed companies from 2006 to 2016 based on the propensity score matching and difference-in-difference method. Results indicate that innovation performance is negatively affected by the direct government subsidies, which is especially significant for non-state-owned enterprises. While the R\&D tax super-deduction policy is significantly improving the innovation performance of the enterprise, whether for state-owned or non-state-owned enterprises, the positive effect is equally significant.
\end{abstract}

\section{Keywords}

Government Subsidies, R\&D Tax Super-Deduction Policy, Innovation Performance of Enterprises

\section{Introduction}

China adheres to science and technology innovation as the first driving force for development and strives to take the lead in technological innovation. However, compared with conventional investment in production and operation, enterprises engaged in technological innovation have the characteristics of high cost, high risk, long cycle and positive externalities. Private investors have the aversion to risk and the preference for stable development, which leads to the phenomenon of "market failure" of insufficient spontaneous supply of enterprises' technological innovation activities. The government directly or indirectly supports enterprise R\&D activities, and encourages enterprise innovation, which is in line with the definition of the government's functions and the law of devel- 
opment under market economy conditions.

At present, the two main ways that Chinese government encourages enterprises to innovate are government subsidies and the tax relief policies. In recent years, China's government subsidies have increased year by year. The data show that the expenditure on new product development reached 1.18 trillion yuan in 2016, an increase of $71.01 \%$ compared with 0.69 trillion yuan in $2011^{1}$. Government subsidies are considered to be strong support for R\&D activities, but there are serious problems such as adverse selection beforehand and moral hazard afterwards [1]. The tax relief policies include enterprise income tax relief and R\&D tax super-deduction. R\&D tax super-deduction policy (according to the provisions of the Tax Law, on the basis of the actual amount of research and development expenses incurred in the development of new technologies, new products and new processes, a certain proportion is added to calculate the deduction amount of taxable income. At present, the proportion is an additional deduction of $75 \%$ ) is based on $R \& D$ costs incurred by enterprises in each period. The more $\mathrm{R} \& \mathrm{D}$ costs are, the greater the tax relief is, which is equivalent to an incentive for enterprises to engage in $\mathrm{R} \& \mathrm{D}$ activities. In other words, the $\mathrm{R} \& \mathrm{D}$ tax super-deduction policy is essentially an indirect form of innovation subsidies. R\&D tax super-deduction policy is universal, and subsidies run through the whole process of R\&D activities. Therefore, it can solve the problems of adverse selection and moral hazard of direct subsidy to a certain extent. The main beneficiaries of the policy are high-tech enterprises. In the past five years, the tax reduction and exemption of high-tech enterprises has been increasing. Among them, the amount of R\&D tax super-deduction policy has accounted for more than $50 \%$ of the total tax reduction and exemption for many consecutive years. At the same time, compared with other forms' tax relief policies, the $\mathrm{R} \& \mathrm{D}$ tax super-deduction policy can reduce the amount of tax payable in a more timely manner, reduce the cost of R\&D by paying less tax, and improve the cash flow of enterprises. Therefore, the policy is more favored by the government and the enterprises.

Scholars at home and abroad have done a lot of research on different ways of innovation subsidies. The following main problems exist in the innovative activities: first, the externalities and high risks of R\&D activities are the fundamental causes of market failure. Second, due to the principal-agent problem, managers prefer to invest in short-term projects with predictable returns rather than R\&D projects. Appropriate government intervention can effectively solve these problems [2] [3]. Scholars give different answers to the effect of government subsidies on innovation activities. As an external driving force to promote technological innovation, government subsidies are positively correlated with R\&D input and output of enterprises, and factors such as knowledge stock, enterprise scale and enterprise age have a certain impact on the effect of subsidies [4]. In addition, government subsidies can also play a signaling role to help enterprises obtain stakeholder resources and support, thus promoting enterprises to improve ${ }^{1}$ China Science and Technology Yearbook, 2017. 
corporate innovation performance [5] [6].

Some scholars believe that government subsidies are short-term and moderate. On the one hand, although innovation subsidies have a positive short-term effect on human capital investment, most enterprises lack a positive performance effect in the long run [7]. On the other hand, companies receiving government R\&D subsidies will have better innovation performance to a certain extent, beyond this threshold, more share of government R\&D subsidies will reduce the innovation performance of enterprises. And the substitution effect is greater for firms with strong R\&D capabilities [8]. Some scholars totally deny the incentive effect of government subsidies on innovation activities. They believe that government subsidies not only have a negative impact on innovation performance, but also increase the risk of collapse of listed companies. Political connections and institutional environment are the main reasons for the ineffectiveness of government subsidies. The more easily the enterprises with political relations with local governments get government subsidies and the worse the institutional environment, the more obvious this rent-seeking phenomenon is. Strengthening anti-corruption work can significantly increase the R\&D investment of enterprises [9] [10]. At present, there are few studies on the R\&D tax super-deduction Policy. Some scholars believe that the intensity of super-deduction is positively correlated with the R\&D investment of enterprises, and the $R \& D$ investment of state-owned enterprises increases more than that of non-state-owned enterprises. The R\&D of enterprises in areas with high degree of marketization increases more than those in areas with low degree of marketization [11] [12]. Some scholars also believe that tax incentives such as R\&D expense plus deduction policy have positive effects on $R \& D$ investment, but due to the lack of strict restraint mechanism and other reasons, the effect of the policy on patent output is not significant [13].

In summary, the existing research mainly discusses the effect of innovation subsidies on R\&D investment, and seldom evaluates the intuitive policy effect of innovation performance. Besides, this paper is a pioneering comparative study of R\&D tax super-deduction Policy and government direct subsidies. PSM-DID method is used to measure the policy effect of the two subsidy modes from innovation performance, which solve the problem effectively of sample selection errors and endogenous problems, and the estimated results are more scientific. Furthermore, this paper studies the impact of nature of enterprise and regional heterogeneity on policy effectiveness, which is great significance to enterprise management and innovation policy implementation.

Based on the sample of A-share listed companies in China from 2006 to 2016, this paper uses the propensity score matching method (PSM) and the difference-in-difference method (DID) to measure the incentive effect of subsidy on enterprise innovation from the perspectives of direct subsidy (government subsidies) and indirect subsidy ( $R \& D$ tax super-deduction Policy). The results show that: 1) Government subsidies have a certain hindrance effect on innovation performance of enterprises. The R\&D expense plus deduction policy has a sig- 
nificant positive stimulus to the innovation performance of enterprises. 2) Considering the heterogeneity of property rights, government subsidies significantly reduce the innovation performance of non-state-owned enterprises, while the Deduction Policy significantly improves the innovation performance of non-state-owned enterprises.

The paper proceeds as follows. Section 2 describes the sample, variables measurement and research design. Section 3 presents the empirical results. Section 4 concludes.

\section{Data, Variables and Method}

\subsection{Sample Selection and Data Sources}

This study uses data collected by author from WIND and CSMAR. Selecting A-share listed companies for which government subsidies information is available from 2006 to 2016 as research initial samples. And the samples of financial industry, $\mathrm{ST}$ and $\mathrm{PT}$, and missing main variables such as R\&D costs and patent applications were deleted. In order to delete the observational values which have obvious statistical errors and don't conform to the accounting standards, we winsorize main continuous variables in $1 \%$ in this paper. Besides, the methods of identifying the beneficiaries of R\&D tax super-deduction Policy are as follows: because the applicable conditions of $\mathrm{R} \& \mathrm{D}$ tax super-deduction policy are that the R\&D activities of enterprises must meet the following three conditions simultaneously: innovative, value, and conform to the "Key State Supported High-tech Areas". Therefore, this paper chooses high-tech enterprises as the beneficiaries of the R\&D tax super-deduction Policy.

\subsection{Variables Definition}

\subsubsection{Innovation Performance}

Following prior literature, scholars often use the amount of patent applications and patent authorization to measure innovation performance. The Patent Law of the People's Republic of China stipulates that patents can be subdivided into invention patents, utility model patents and design patents. Compared with invention patents, the other two types of patents have low technical requirements, and invention patents can better represent the innovation ability of enterprises [13] [14]. Therefore, this paper chooses the logarithm of patent application plus 1 to measure innovation performance.

\subsubsection{Variables of Policy}

SUB is a dummy variable of government direct subsidies. If an enterprise receives a government subsidy, the SUB value is 1 , otherwise 0 . POL is the dummy variable of R\&D expense plus deduction policy time, 2008 is the time to implement the policy of R\&D tax super-deduction, so before 2008, the value of POL is 0 , in 2008 and beyond, the value of POL is 1 . GRO is a grouping variable of R\&D tax super-deduction Policy. In 2008, the GRO value of the high-tech enterprise qualifications sample is 1 , otherwise 0 . The cross-term coefficient measures the 
impact of the R\&D tax super-deduction Policy on the innovation performance of the enterprise.

\subsubsection{Control Variables}

This paper controls the relevant variables such as enterprise size (ASSET), enterprise income tax rate (TAXR), debt level (LEV), enterprise growth (GROWTH), enterprise age (AGE), enterprise capital liquidity (CASH), etc. The detailed variable definitions are shown in Table 1.

\subsection{Method and Model Settings}

\subsubsection{Propensity Score Matching (PSM)}

This paper mainly studies the incentive effect of innovation subsidies on innovation performance from two perspectives of government subsidies policy and R\&D tax super-deduction Policy. On the one hand, the beneficiaries of innovation subsidies are mainly concentrated in the high-tech industries supported by the national key development. Actually, whether enterprises benefit from innovation subsidy policy is a non-random event because of the influence of the will of the government. On the other hand, when estimating the additional incentive effect of innovation subsidies, it is necessary to separate which parts of innovation performance are generated by innovation subsidies rather than by the original decision-making of the enterprise itself. Therefore, this paper chooses the Propensity Score Matching (PSM) method which can effectively solve the sample selection bias. The basic idea is to construct the control group with the closest characteristics to the beneficiary sample based on the enterprises without innovation subsidies, to ensure that the covariates of the treatment group and the control group samples are as similar as possible except this factor of receiving innovation subsidies. The effect of innovation subsidies on innovation performance can be expressed as follows:

$$
E\left(Y_{i}\right)=E\left(Y_{i}^{Y} \mid S=1\right)-E\left(Y_{i}^{N} \mid S=1\right) .
$$

Table 1. Definition of variables.

\begin{tabular}{|c|c|c|}
\hline Variables & symbols & Descriptions \\
\hline $\begin{array}{l}\text { Dependent } \\
\text { Variable }\end{array}$ & IPATENT & $\begin{array}{l}\text { The natural logarithm is taken after the number of patent } \\
\text { applications for inventions of enterprises is added to } 1\end{array}$ \\
\hline \multirow{3}{*}{$\begin{array}{l}\text { Independent } \\
\text { Variables }\end{array}$} & SUB & $1=$ Get Government Subsidies, $0=$ No government subsidies \\
\hline & GRO & Grouping variables of R\&D tax super-deduction Policy \\
\hline & POL & $1=$ Treatment group, $0=$ Control group \\
\hline \multirow{6}{*}{ Control Variables } & ASSET & Logarithm of total assets of a company \\
\hline & TAXR & Enterprise income tax rate \\
\hline & LEV & Asset-liability ratio \\
\hline & GROWTH & Income growth rate \\
\hline & AGE & Sample year minus year of establishment plus 1 \\
\hline & CASH & Net operating cash flow divided by final total assets \\
\hline
\end{tabular}


where $S$ is the group variable whether the enterprise receives innovation subsidies, if the enterprise is a subsidized enterprise, $S$ equals $1 . Y_{i}^{Y}$ is the innovation performance of company $i$, and $Y_{i}^{N}$ indicates the subsidized companies' innovation performance when supposed they did not receive the subsidies, $E\left(Y_{i}\right)$ can be approximated as the additional innovation performance brought about by innovation subsidies, but $Y_{i}^{N}$ is a unobservable variables. To solve this problem, we select a set of variables and use the propensity score matching method to transform these variables into one-dimensional variables to synthesize a score. According to the propensity score, we construct a control group that matches the subsidized enterprises in the treatment group.

\subsubsection{Difference-in-Difference (DID)}

When discussing the incentive effect of the R\&D tax super-deduction Policy on innovation performance, this paper further evaluates the policy effect by using difference-in-difference method on the basis of propensity score matching. Since the promulgation of the "Measures for the Management of the Recognition of High-tech Enterprises" in 2008, the recognition of high-tech enterprises has been strictly filed for examination and approval, and the recognition work has only begun to standardize, therefore setting 2008 as the dividing point of the dummy variable of policy time. Moreover, the time for enterprises to be identified as high-tech enterprises is different. In order to ensure the adequacy of samples, the samples that were continuously recognized as high-tech enterprises from 2008 were selected as the treatment group. To estimate the effect of policy implementation, we set the following DID model:

$\mathrm{IPATENT}_{i t}=\beta_{0}+\beta_{1} \mathrm{GRO}_{i} \times \mathrm{POL}_{t}+\lambda \sum \mathrm{CONTROL}_{i t-1}+\sum$ Industry $+\sum$ Year $+\varepsilon_{i t}$ where IPATENT $_{i t}$ is the innovation performance for company $i$ at the end of period $t$. The coefficient $\beta_{1}$ reflects the effect of R\&D tax super-deduction Policy on enterprise innovation. Because of the lag of R\&D activities, the control variables in this paper are dealt with in a lag period.

\section{Results}

\subsection{Variable Description}

From Table 2, we can see that the sample observation value of innovation performance is 11,714 , the average value is 1.7016 , the standard deviation is 1.2290 , the minimum value is 0 , and the maximum value is 5.631 . This shows that there are great differences in the application amount of invention patents among different enterprises. The mean value of the policy dummy variable of government subsidies is 0.7495 , which indicates that $75 \%$ of enterprises in the sample have received government subsidies. The minimum value of enterprise income tax rate is 0 , because some enterprises enjoy the state exemption of enterprise income tax policy, the maximum value is 33 , and the standard deviation is 5.8014 . This shows that the income tax rates of different enterprises are quite different. Controlling the impact of enterprise income tax rate can better study the implementation effect of innovation subsidies. 
Table 2. Description Statistical of Data.

\begin{tabular}{cccccc}
\hline Variables & Obs & Mean & Sd & Min & Max \\
\hline IPATENT & 11714 & 1.7016 & 1.2290 & 0 & 5.6240 \\
SUB & 21494 & 0.7495 & 0.4333 & 0 & 1 \\
TAXR & 20261 & 17.6315 & 5.8014 & 0 & 33 \\
LEV & 16199 & 0.4126 & 0.2084 & 0.0445 & 0.8919 \\
CASH & 16199 & 0.0455 & 0.0701 & -0.1541 & 0.2463 \\
AGE & 21494 & 17.3299 & 5.0344 & 7 & 29 \\
GROWTH & 14665 & 0.1917 & 0.4135 & -0.4620 & 2.6803 \\
ASSET & 16199 & 21.8292 & 1.2503 & 19.5926 & 25.8612 \\
IPATENT & 11714 & 1.7016 & 1.2290 & 0 & 5.6240 \\
\hline
\end{tabular}

a) Retain four-digit significant digits after decimal points of some data.

\subsection{Evaluation Results of Two Innovation Policies}

Firstly, the PSM method is used to select the treatment group and the control group for innovation subsidies. As the main reference factors for enterprises to obtain innovation subsidies are enterprise income tax rate, debt level, enterprise growth, enterprise age, enterprise capital liquidity, enterprise scale, etc. the above variables are selected as the characteristic variables of the enterprise to calculate the score of the covariate by regression. Scores for the treatment group enterprises to find matching control enterprises.

\subsubsection{Estimation of Government Subsidies}

Table 3 shows the average treatment effect on the treated (ATT) of government subsidies, ATT stands for the average difference in innovation performance between the policy-affected treatment group and the control group. From the result of ATT, we can know that compared with unmatched, the difference in innovation performance of the two groups after matching declined significantly. The reason is that the matched sample excludes the factors of their own higher innovation performance. The average innovation performance of the matched treatment group is 1.7853 , while that of the control group is 1.8654 . The average innovation performance of the control group is higher than that of the treatment group. This means that government subsidies can't promote the innovation performance of enterprises, but produce "crowding-out effect", which is fortunate that the crowding-out effect is not significant.

\subsubsection{Estimation of R\&D Tax Super-Deduction Policy}

In theory, after the implementation of the R\&D tax super-deduction Policy, it reduces the $R \& D$ cost of enterprises, releases positive signals to the market, improves the financing level of enterprises, and thus improves the R\&D investment of enterprises. Increasing $R \& D$ investment will improve $R \& D$ efficiency, reduce $\mathrm{R} \& \mathrm{D}$ risks, and then improve innovation performance.

Table 4 shows the results of the difference-in-difference estimates of the R\&D 
Table 3. ATT of government subsidies.

\begin{tabular}{ccccccc}
\hline Variable & Sample & Treated & Controls & Difference & S.E. & T-stat \\
\hline \multirow{2}{*}{ IPATENT } & Unmatched & 1.7853 & 1.4427 & 0.3425 & 0.0309 & $11.07^{* * *}$ \\
& Matched & 1.7853 & 1.8654 & -0.0802 & 0.0550 & -1.46 \\
\hline
\end{tabular}

a) Retain four-digit significant digits after decimal points of some data. b) ${ }^{*} \mathrm{p}<0.10,{ }^{* *} \mathrm{p}<0.05,{ }^{* *} \mathrm{p}<0.01$.

Table 4. Difference-in-difference estimates.

\begin{tabular}{|c|c|c|c|c|}
\hline & \multicolumn{4}{|c|}{ Coefficients and Standard Errors } \\
\hline & (1) & (2) & (3) & (4) \\
\hline \multirow[t]{2}{*}{$\mathrm{POL} \times \mathrm{GRO}$} & $0.423^{* * *}$ & $0.305^{* * *}$ & $0.441^{* * *}$ & $0.265^{\star * *}$ \\
\hline & $(0.028)$ & $(0.063)$ & $(0.030)$ & $(0.046)$ \\
\hline \multirow[t]{2}{*}{ TAXR } & & & $-0.037^{\star * \star}$ & $-0.027^{\star * *}$ \\
\hline & & & $(0.003)$ & $(0.004)$ \\
\hline \multirow[t]{2}{*}{ LEV } & & & -0.126 & -0.025 \\
\hline & & & $(0.084)$ & $(0.109)$ \\
\hline \multirow[t]{2}{*}{ GROWTH } & & & 0.067 & 0.010 \\
\hline & & & $(0.041)$ & $(0.038)$ \\
\hline \multirow[t]{2}{*}{ CASH } & & & $0.942^{* * *}$ & $1.409^{* * *}$ \\
\hline & & & $(0.208)$ & $(0.282)$ \\
\hline \multirow[t]{2}{*}{ AGE } & & & -0.003 & -0.002 \\
\hline & & & $(0.003)$ & $(0.004)$ \\
\hline \multirow[t]{2}{*}{ ASSET } & & & $0.458^{* * *}$ & $0.498^{* * *}$ \\
\hline & & & $(0.013)$ & $(0.030)$ \\
\hline Industry & & $\mathrm{Y}$ & & $\mathrm{Y}$ \\
\hline Year & & $\mathrm{Y}$ & & Y \\
\hline Province & & $\mathrm{Y}$ & & $\mathrm{Y}$ \\
\hline $\mathrm{N}$ & 8124 & 8119 & 6837 & 6836 \\
\hline R2 & 0.028 & 0.173 & 0.205 & 0.320 \\
\hline
\end{tabular}

a) Standard errors in parentheses, ${ }^{*} \mathrm{p}<0.10,{ }^{* *} \mathrm{p}<0.05,{ }^{* *} \mathrm{p}<0.01$. b) "Y" stands for fixed effect.

tax super-deduction Policy. Column (1) and (2) are the basic regression, without adding control variables, and column (2) fixed effects of industries, years and regions. Control variables are added in column (3) and (4), Regression results show: whether related variables are controlled, the significance and the direction of symbols of cross-term coefficients has not been changed, which are significantly positive at the $1 \%$ significant level. That's to say, after the implementation of the R\&D tax super-deduction Policy in 2008, the innovation performance of enterprises affected by the policy has been significantly improved. Therefore, this paper concludes that the effect of R\&D tax super-deduction Policy on enterprise innovation performance is positive. 


\subsection{Analysis of Heterogeneity}

Based on a preliminary study of the incentive effect of government direct subsidies and R\&D tax super-deduction Policy on enterprise innovation performance, the paper also explores the effect of heterogeneous factors on the implementation of innovation subsidies policy.

Due to the differences of leadership promotion mechanism, management mode and age structure of employees between state-owned enterprises and non-state-owned enterprises, innovation subsidies may have different effects on enterprises with different ownership nature. In order to investigate the difference of innovation performance between state-owned enterprises and non-state-owned enterprises after they receive innovation subsidies, this paper classifies the samples into state-owned enterprises and non-state-owned enterprises, explores the incentive effect of two main innovation subsidies forms on innovation performance.

\subsubsection{The Impact of the Ownership Nature on Government Subsidies} According to the classification of ownership nature, the ATT of government subsidies is shown in Table 5. The results show that the innovation performance of state-owned enterprises is not significantly affected by the government subsidy policy after sample matching, but for non-state-owned enterprises, the government subsidies have a reverse effect on innovation performance at a significant level of $5 \%$. That is to say, the government subsidies not only fail to achieve the purpose of stimulating enterprise innovation, but also reduce innovation performance.

The reasons for this result may be as follows: Firstly, the innovation activities themselves have high cost and long cycle, and most of the government subsidies belong to prior subsidies. For enterprises with large financing constraints, especially non-state-owned enterprises, it is difficult to maintain the long-term stable supply of funds needed for R\&D activities, so the policy effect is not significant. Secondly, besides the innovative behavior aimed at promoting technological progress and maintaining competitive advantage, there are also "strategic innovations" that enterprises are engaged in "seek support". This kind of "strategic innovation" occurs more frequently in non-state-owned enterprises with capital disadvantages and high financing costs. When companies expect to receive more government subsidies, the amount of non-invention patent applications increases

Table 5. ATT of government subsidies.

\begin{tabular}{ccccccc}
\hline Variable & Sample & Treated & Controls & Difference & S.E. & T-stat \\
\hline $\begin{array}{c}\text { State-owned } \\
\text { enterprises }\end{array}$ & Unmatched & 1.9871 & 1.4510 & 0.5361 & 0.0487 & $11.02^{* * *}$ \\
$\begin{array}{c}\text { Matched } \\
\begin{array}{c}\text { Non-state-owned } \\
\text { enterprises }\end{array}\end{array}$ & 1.9796 & 1.8670 & 0.1126 & 0.0755 & 1.49 \\
\hline
\end{tabular}

a) Retain four-digit significant digits after decimal points of some data. b) ${ }^{*} \mathrm{p}<0.10,{ }^{* *} \mathrm{p}<0.05,{ }^{* *} \mathrm{p}<0.01$. 
significantly, which will squeeze out the number of applications for invention patents [15].

\subsubsection{The Impact of the Ownership Nature on R\&D Tax Super-Deduction Policy}

In theory, the R\&D tax super-deduction Policy runs through the whole process of enterprise innovation activities, which can ease the constraints of enterprise financing and provide a certain degree of support for the various periods of innovation activities. Therefore, the policy effect will be more effectively transmitted to the innovation output and improve the innovation performance.

Table 6 reflects the changes in innovation performance of state-owned and non-state-owned enterprises after they benefit from $\mathrm{R} \& \mathrm{D}$ tax super-deduction Policy. The results show that after the implementation of R\&D tax super-deduction Policy, whether for state-owned or non-state-owned enterprises, the innovation performance of the treatment group enterprises is significantly higher than that of the control group enterprises at the level of $5 \%$ and $1 \%$, respectively. This shows that the policy can improve the innovation performance of enterprises and achieve the goal of policy formulation.

Table 6. Difference-in-difference estimates.

\begin{tabular}{|c|c|c|}
\hline & \multicolumn{2}{|c|}{ Coefficients and Standard Errors } \\
\hline & State-owned enterprises & Non-state-owned enterprises \\
\hline \multirow[t]{2}{*}{$\mathrm{POL} \times \mathrm{GRO}$} & $0.252^{\star *}$ & $0.242^{\star * *}$ \\
\hline & $(0.105)$ & $(0.056)$ \\
\hline \multirow[t]{2}{*}{ TAXR } & $-0.032^{\star * *}$ & $-0.031^{\star * \star}$ \\
\hline & $(0.005)$ & $(0.005)$ \\
\hline \multirow[t]{2}{*}{ LEV } & $-0.503^{* *}$ & 0.245 \\
\hline & $(0.240)$ & $(0.153)$ \\
\hline \multirow[t]{2}{*}{ GROWTH } & -0.054 & 0.041 \\
\hline & $(0.061)$ & $(0.046)$ \\
\hline \multirow[t]{2}{*}{$\mathrm{CASH}$} & $1.177^{\star *}$ & $1.810^{* * *}$ \\
\hline & $(0.517)$ & $(0.277)$ \\
\hline \multirow[t]{2}{*}{ AGE } & -0.014 & 0.002 \\
\hline & $(0.013)$ & $(0.004)$ \\
\hline \multirow[t]{2}{*}{ ASSET } & $0.557^{* * *}$ & $0.456^{* * *}$ \\
\hline & $(0.044)$ & $(0.059)$ \\
\hline Industry & $\mathrm{Y}$ & Y \\
\hline Year & $\mathrm{Y}$ & $\mathrm{Y}$ \\
\hline Province & $\mathrm{Y}$ & $\mathrm{Y}$ \\
\hline $\mathrm{N}$ & 2636 & 4196 \\
\hline R2 & 0.456 & 0.269 \\
\hline
\end{tabular}

a) Standard errors in parentheses, ${ }^{\star} \mathrm{p}<0.10,{ }^{* *} \mathrm{p}<0.05,{ }^{* * *} \mathrm{p}<0.01$. b) "Y" stands for fixed effect. 


\section{Conclusions}

This paper makes a comparative study of the effects of government subsidies and $\mathrm{R} \& \mathrm{D}$ tax super-deduction policy on innovation performance of enterprises. The study found that government subsidies not only did not improve the innovation performance of enterprises, but also reduced it, especially for non-state-owned enterprises. The reasons are as follows. Firstly, the choice of government subsidy is too strongly influenced by the will of the government, which easily breeds a series of problems, such as rent-seeking, "strategic innovation" and so on. Secondly, the government's direct subsidies mostly use one-off subsidies funds in advance, while the innovation activities have a long cycle. The policy ignores the financing constraints during the enterprise's innovation activities. In the research on the policy of R\&D tax super-deduction, we find that the policy has a significant effect on the innovation performance of enterprises. It isn't affected by the nature of enterprise ownership. The results show that after the implementation of the R\&D tax super-deduction policy, the innovation performance of both state-owned enterprises and non-state-owned enterprises has been significantly improved. There are two reasons for the remarkable effect of R\&D tax super-deduction policy on enterprise innovation. Firstly, the policy subsidy runs through the whole process of innovation activities and can alleviate enterprise financing constraints to a certain extent. Secondly, the tax reduction of this policy is based on the R\&D expenditure generated by $R \& D$ activities of enterprises in each period. The more R\&D expenditure is, the greater the tax relief will be. Therefore, in the process of implementing this policy, the problems such as "rent-seeking" and strategic innovation can be effectively avoided.

To sum up, the R\&D tax super-deduction policy is more effective than the government direct subsidy in improving enterprise innovation performance. Therefore, the following suggestions are put forward: the government should play a leading role in encouraging enterprise innovation rather than leading role. Government should put market allocation resources at the core and reduce the government's will. In other words, the government should reduce direct government subsidies and expand the publicity and implementation of the policy of $\mathrm{R} \& \mathrm{D}$ tax super-deduction. On the other hand, enterprises should not adopt strategic innovation for "seeking support", which will not only increase their unnecessary friction costs, but also produce negative external effects to destroy the market innovation environment. Enterprises should make correct innovation decisions according to their own strength and long-term development plan.

\section{Acknowledgements}

Thank my teachers and classmates for their help in the thinking and empirical analysis of my article. Thank the editor for his many suggestions on the article.

\section{Conflicts of Interest}

The author declares no conflicts of interest regarding the publication of this paper. 


\section{References}

[1] An, T.L., Zhou S.D. and Pi, J.C. (2009) The Stimulating Effects of R\&D Subsidies on Independent Innovation of Chinese Enterprises. Economic Research Journal, 10, 87-98.

[2] Arrow, K.J. (1962) The Economic Implication of Learning by Doing. Review of Economic Studies, 2, 155-173. https://doi.org/10.2307/2295952

[3] Hall, B.H. and Van Reenen, J. (2000) How Effective Are Fiscal Incentives for R\&D? A Review of the Evidence. Research Policy, 5, 449-469. https://doi.org/10.1016/S0048-7333(99)00085-2

[4] Zhang, S. and Zhao, X. (2018) Public Subsidy and R\&D Input and Output in Emerging Sectors of Strategic Importance. Journal of Tianjin University, 6, 495-502.

[5] Bai, J.H. (2011) Are Government R\&D Subsidies Efficient in China? Evidence from Large and Medium Enterprises. China Economic Quarterly, 10, 1375-1400.

[6] Wu, J., Tian Z.L., Long, X.F. and Xiong, Q. (2018) The Impact of Government Subsidies on Corporate Innovation in Strategic Emerging Industries. Studies in Science of Science, 36, 158-166.

[7] Gustafsson, A., Stephan, A., Hallman, A. and Karlsson, N. (2016) The "Sugar Rush" from Innovation Subsidies: A Robust Political Economy Perspective. Empirica, 4, 729-756. https://doi.org/10.1007/s10663-016-9350-6

[8] Zhang, X.D. and Wu, J.J. (2014) Research on Effectiveness of the Government R\&D Subsidies: Evidence from Large and Medium Enterprises in China. American Journal of Industrial and Business Management, 9, 503-513.

https://doi.org/10.4236/ajibm.2014.49056

[9] Yu, M.G., Tian, Y.F., and Pan, H.B. (2010) Political Connections, Rent Seeking, and the Fiscal Subsidy Efficiency of Local Governments. Economic Research Journal, 3, 65-77.

[10] Wang, Q. and Liang, Y. (2017) Anti-Corruption, Government Subsidies and Corporate Innovation Investment-Based on the Perspective of Rent-Seeking Theory. Chinese Studies, 1, 44-54.

[11] Liu, X., He, Y. and Yang, D.W. (2012) The Implementing Effect of R\&D Expenditure Increment and Deduction: An Empirical Study Based on Small and Medium-sized Listed Companies in Shenzhen Stock Market. Macroeconomics, 9, 87-92.

[12] Chen, H.S. and Tao, Y.H. (2016) The Impact of R\&D Tax Super-Deduction Policy on R\&D Investment of Enterprises: A Case Study of A-Share High-Tech Listed Companies. Finance and Accounting Monthly, 29, 11-16.

[13] Zhu, P.F. and Xu, W.M. (2003) On the Impact of Government's S\&T Incentive Policy on the R\&D Input and Its Patent Output of Large and Medium-Sized Industrial Enterprises in Shanghai. Economic Research Journal, 6, 45-53.

[14] Yu, M.G., Fan, R. and Zhong, H.J. (2016) Chinese Industrial Policy and Corporate Technological Innovation. China Industrial Economics, 12, 5-22.

[15] Li, W.J. and Zheng, M.N. (2016) Is It Substantive Innovation or Strategic Innovation? Impact of Macroeconomic Policies on Micro-Enterprises' Innovation. Economic Research Journal, 4, 60-73. 